\title{
EFFECTS OF CRYOGENIC TREATMENT ON TOOL STEEL AISI-D6
}

\author{
Arvind Kaushal ${ }^{1}$, R.S.Rajput ${ }^{2}$, Ajay $\operatorname{Vardhan}^{3}$ \\ ${ }^{I}$ Guest Faculty Mech. Engg. (IGEC Sagar) \\ ${ }^{2}$ System Analyst (D.T.E. Bhopal) \\ ${ }^{3}$ Student M.Tech.
}

\begin{abstract}
In present technological modern age. All the manufacturers adopt that process which governs to higher productivity that has been achieved by the various treatment of tool steel. These conventional processes improve no of characteristics to fulfill desired purpose. But all these process does not provided fully satisfaction from conventional heat treatment process. Thus a new process is being additionally employed for improving mechanical properties called cryogenic treatment process or sub-zero treatment of tool steels. During this process tool steel is proceed below Atmospheric tem. That is in minus about $\left(-196^{\circ} \mathrm{C}\right.$ or $\left.310^{\circ} \mathrm{F}\right)$. Due to cooling, steel alter their mechanical properties like wear resistance, Hardness, toughness, fatigue life micro-structure alteration etc. Cryo-treatment not only improve its mechanical properties but also improve thermal properties, electrical properties \& easier machining etc. in this paper cryogenic treatment of tool steel AISI-D6 is perform and study is made for wear-resistance, Hardness, toughness, with respect to untreated test specimen of same, we have got improved wear-resistance capacity improve hardness as well as toughness.
\end{abstract}

Keywords - AISI-D6 tool steel, cryogenic process, wear resistance, Hardness, Toughness.

\section{INTRODUCTION}

Cyrogenic treatment process is associated with the Heat treatment process. Additionally throughout this process work piece is processed in the present of liquid nitrogen below Atmospheric tem. Or $-196^{\circ} \mathrm{C}\left(310^{\circ} \mathrm{F}\right)$ the cryogenic technology established process for the production of tool steel for the most different technical application (1-4). In previous duration of technology Heat treatment of steel was done to achieved improved wear-resistance capacity improved toughness, stress relieving also. All the properties are improved but their Austenitic crystal structure remain same after the process which is soft in nature. After applying the cryo-treatment Austenite is permanently transform into the martensite structure which represent permanent change in micro structure. This martensite structure definitely increased wear-resistance capacity, toughness, microstructure relieve all the stress thus mechanical property is in increasing order Basically All these improved charactertics are result of formation OR transformation of mantensite from Austenite structure which is soft phase of iron and carbon atom $\{8\}$. This un-transformed Austenite is Brittle and lake of undurability, which allows the metal to break under minimum application of loads. Due to phase trams formation conversion of Austenite to martensite take place, which has tetragonal crystal structure martensite is Harder material (appear carbide) having a high wear resistance Better stability, represent- better resistance to plastic deformation due to closed packed iron atoms with the carbon atoms. Cold treatment is generally classified as either sub-zero treatment or sleep cryogenic treatment. After cryotreatment. We can controlled the desired property that is not eliminated through conventional heat treatment, getting reduced tool consumption and now time for equipments setup thus leading to cost reduction of about $50 \%$. The
Greatest improvement in properties is obtained by selecting proper heat treatment process sequence, soaking time, stabilization, hardening temperature, heating and cooling Rate $[7,8,9,10]$. The cryogenic treatment is conducted on tool steel margening material tool, cost steel carburized. This process is also used in Aircraft automobile industries as well as many others area to enhance mechanical process application. Cryogenic processing (CP) is presently employed in the field like aero-space \& manufacturing industries sports and music industries fire arm etc. In the last decade a good no of Investigators have been directed to improve the tribological properties like wear resistance of steel die steel by cryotreatment. Treatment of tooling is a proven technology to increase war resistance. Extent interval between component replacements for dies, punches, drill bits end mills cutter. Bearing cams crunch-shaft blocks pistons blades etc. controlled C.P. is commonly applied in between conventional hardening and tempering for tool die steel. $^{2}$ AISID $_{6}$ tool steel process high wear and abrasion resistance, high alloys contents excellent dimensional stability. Following are the major field of application measuring tool, blanking dies, forming dies, coining forming rolls, master tool, shear blades intricate punches, wear parts, mill rolls etc. 


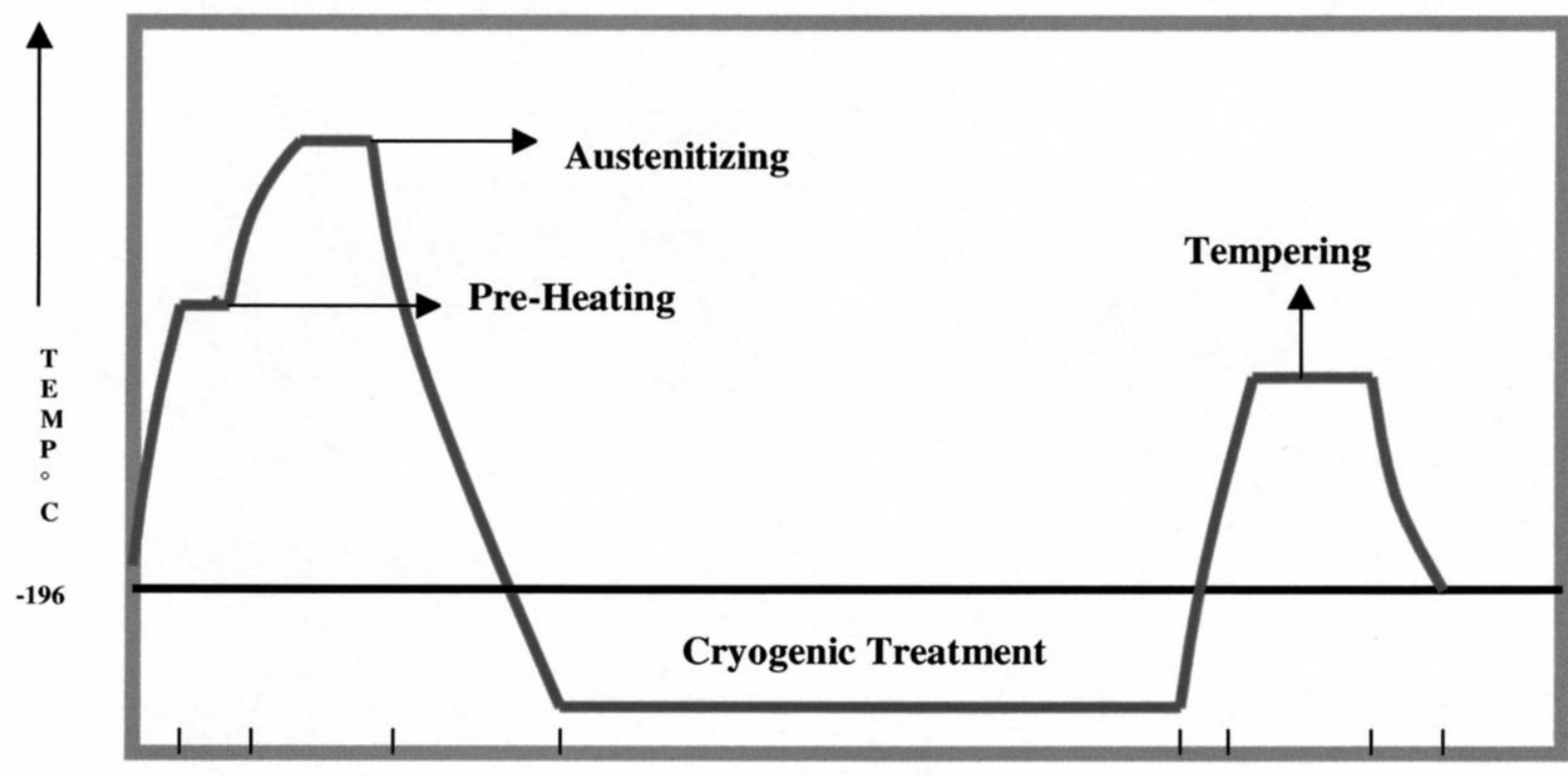

\section{Time in Hrs -> \\ Cryogenic Treatment Cycle}

\section{CRYOGENIC TREATMENT PROCEDURE}

\section{OR METHODOLOGY}

In this paper test specimen of $\mathrm{AISi}-\mathrm{D}_{6}$ is processed length of atom (20mm Dia \& $45 \mathrm{~mm}$ length) has been taken, the liquid $\mathrm{N}_{2}$ as generated from the $\mathrm{N}_{2}$ plant is store \& storage vessels with the help of transfer lines it is directed to a closed vaccum evacuated chamber called freezer through the nozzles. The supply of liquid $\mathrm{N}_{2}$ into the cryo-frezzer is operated with the help of solenoid valves. Inside the chamber gradual cooling occurs at a predefined role/min of the room temperature of $-187^{\circ} \mathrm{C}$. Once the subzero temperature is reached specimen hold up to $36 \mathrm{Hrs}$ in cryofreezer with continuous supply of $\mathrm{LN}_{2}$. For cryotreatment cryoprocessor is used which can employed for cooling at shallow subzero, deep subzero, cryogenic treatment having a computerized software program that control $\mathrm{LN}_{2}$ flow through solenoid value as per the demand OR rate at which it requires. When $\mathrm{LN}_{2}$ enters the cryo-processor, it gasified immediately through multi hole slitter \& cooling of spacemen takes place. Temperature both is sensed using Resistance temperature detected. Which provide online feedback of temperature of the both to regulate flow of liquid Nitrogen the schematic diagram is given below.

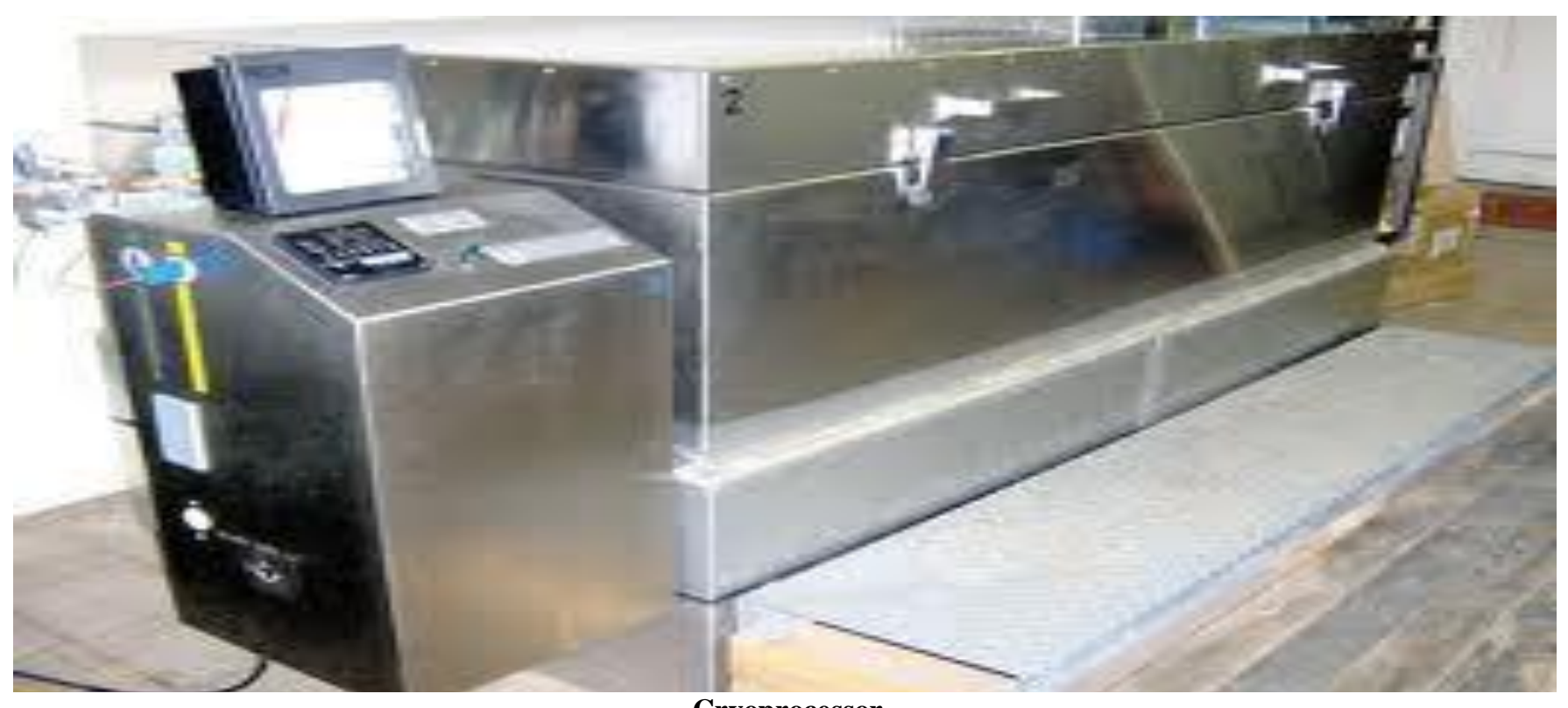

Cryoprocessor 
In the present work the specimen were cryo treated $-187^{\circ} \mathrm{C}$, the soaking time was selected $36 \mathrm{Hrs}$ the both was allowed to cool down slowly (rate $3-4^{0} \mathrm{C} / \mathrm{min}$ ) to avoid thermal shocks. After completing te above process, specimen left to adopt room temperature for about 24 Hrs. a ray diagram gives a clean vision of the process.

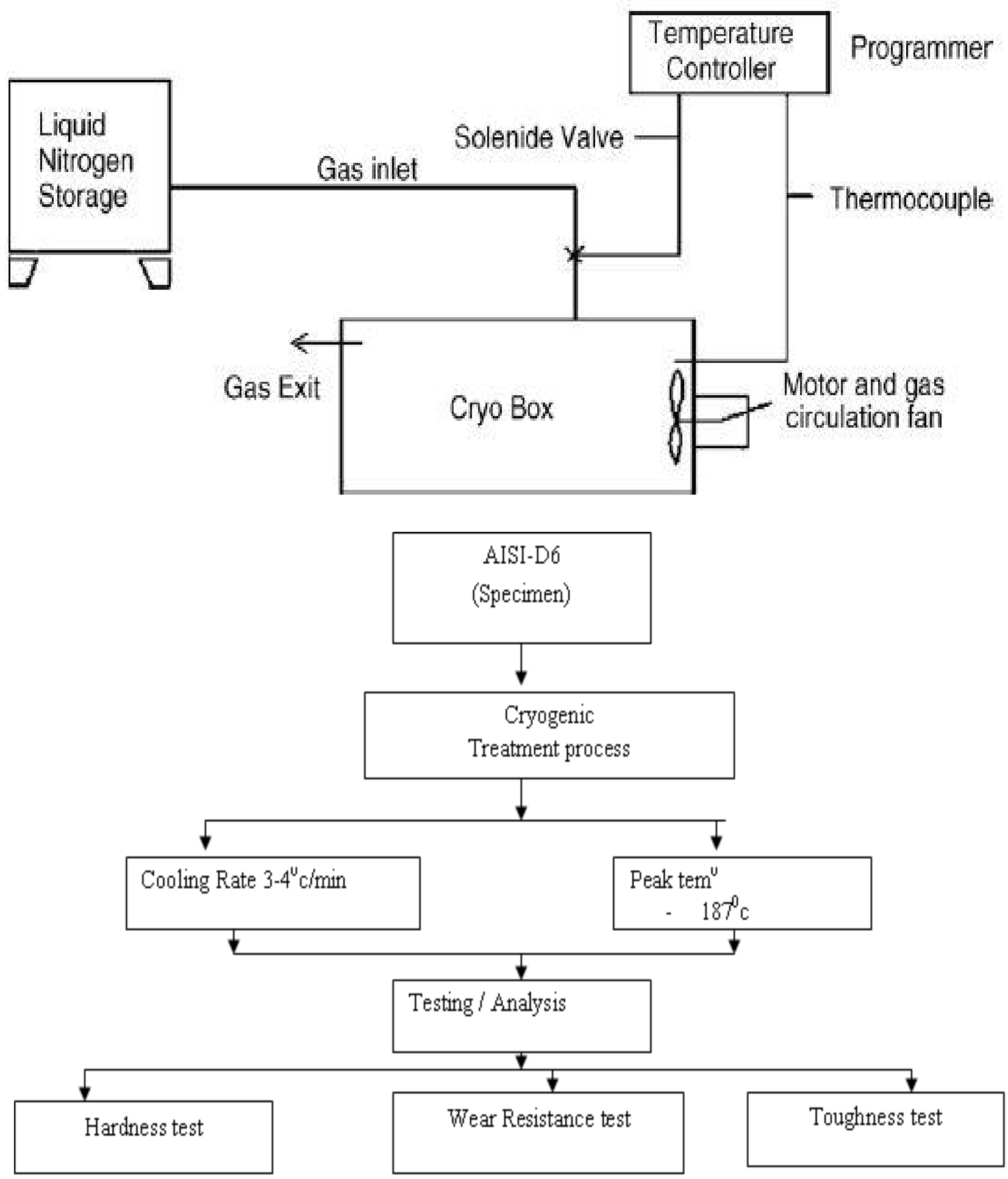

Ray Diagram for Process

\subsection{Hardness Testing}

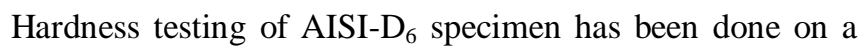
vicker hardness testing machine. Hardness is initiated with minor lead $20 \mathrm{Kg}$ \& major lead of $1200 \mathrm{Kg}$ Hardness is about 745 (VHN) after cryogenic treatment \& Before $720(\mathrm{VHN})$. 


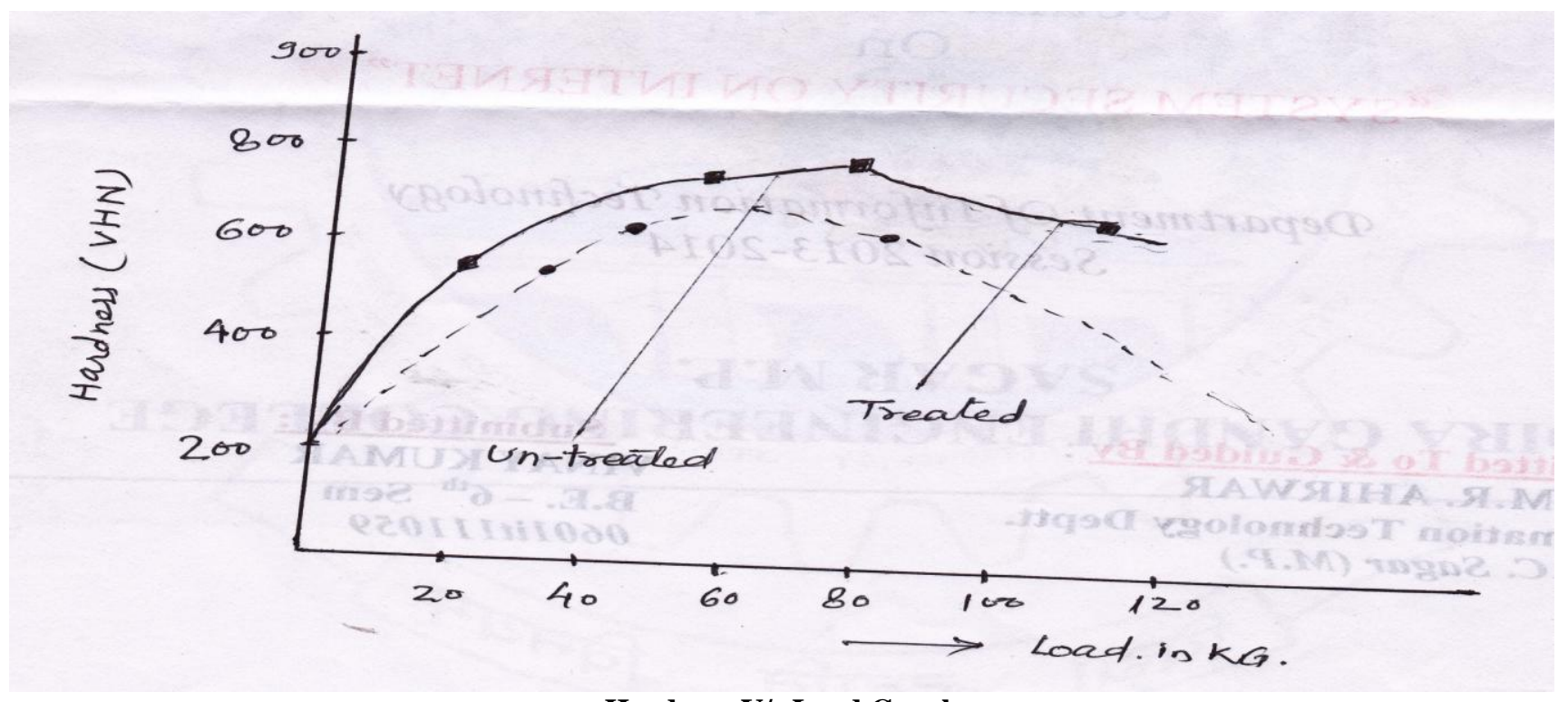

Hardness V/s Load Graph

\subsection{Wear Test-}

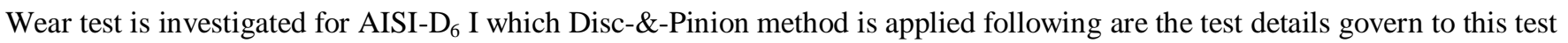

\begin{tabular}{|l|l|l|l|}
\hline S.No. & Normal Load (Kg,N) & Pressure $(\mathrm{Mpa})$ & Velocity V(m/s) \\
\hline 1. & $3.1,30.41$ & $0.4573 \quad \uparrow$ & 1.5 \\
\hline 2. & $3.1,3041$ & $0.4572 \uparrow$ & 2.5 \\
\hline 3. & $5.1,50.03$ & $0.7528 \uparrow$ & 1.5 \\
\hline 4. & $5.1,50.03$ & 0.7523 & 2.5 \\
\hline
\end{tabular}

Wear rates is calculate with help of volumetric method, it is observed that the cryogenically treated specimen have in less wear as compared to conventional heat treatment specimen for conventional heat treatment volume removed is about $10385 \mathrm{~mm}^{2} \& 1.692 \mathrm{~mm}^{3}$ In case of cryogenicallytreated tool steel D-6. Since several researchers' support to the cryogenic treatment process because it improves wears resistance of the material or metals. Throughout the cryotreatment. All the remaining austenite converted into martensite which has improved crystal structure \& their performance.

\subsection{Toughness}

Toughness test is performed by charpy testing method. It is nothing but also a property of metal to absorbed a energy up to before failure. Toughness of AISI-D6 is improved due to reduction in retain austentic decreases \& improvement of martensite increases.

\section{RESULT \& CONCLUSION}

Cryogenic treatment procedure is real supplementary process for alerting the mechanical properties of tool steel. Because it transform the Austenite to marten site. Thereby Hardness wear resistance as well as toughness is increases. It is best method should be applied after conventional heat treatment procedure.

\section{REFERENCES}

[1]. Molinari, M. Pellizzari, S. Gialanella, G. Straffelini, K.H.Stiasny "Effect of deep cryogenic treatment on the properties of tool steel"Journal of Materials Processing Technology 118 (2001) 350-355

[2]. M. H. Staia, Y. Perez-Delgado, C. Sanchez, A. Castro, E. Le Bourhis, E.S. Puchi-Cabrera; "Hardness properties and high-temperature wear behavior of nitrided AISI D2 tool steel, prior and after PAPVD coating"; Wear 267 (2009), pp 1452-1461.

[3]. D. Dasa, A.K. Duttab, K.K. Rayc "Correlation of microstructure with wear behaviour of deep cryogenically treated AISI D2 steel"; Wear 267 (2009) 1371-1380

[4]. Foad Farhani a, Keyvan Seyedi Niaki a, Seyed Ebrahim Vahdat b,c, Amir Firozi "Study of effects of deep cryotreatment on mechanical properties of 1.2542 tool steel"; Materials and Design 42 (2012) 279-288

[5]. D. Dasa, K.K. Rayb, A.K. Duttac, "Influence of temperature of sub-zero treatments on the wear behaviour of die steel"; Wear 267 (2009) 1361-1370

[6]. Bahramia, S.H. Mousavi Anijdana, M.A. Golozarb, M. Shamanianb, N. Varahrama "Effects of conventional heat treatment on wear resistance of AISI H13 tool steel" ; Wear 258 (2005) 846-851

[7]. O. Barrau a, C. Boher, R. Gras b, F. Rezai-Aria a "Analysis of the friction and wear behavior of hot work tool steel for forging"; Wear 255 (2003) 1444-1454 